\title{
Cestode larvae Diphyllobothrium dendriticum as a cause of heart disease leading to mortality in hatchery-reared sea trout and brown trout
}

\author{
Riitta Rahkonen ${ }^{1, *}$, Jarmo Aalto $^{2}$, Perttu Koski ${ }^{3}$, Jukka Särkkä ${ }^{4}$, Keijo Juntunen ${ }^{2}$ \\ ${ }^{1}$ Finnish Game and Fisheries Research Institute, PO Box 202, FIN-00151 Helsinki, Finland \\ ${ }^{2}$ Muonio Fish Farm, FIN-99300 Muonio, Finland \\ ${ }^{3}$ National Veterinary and Food Research Institute, Regional Laboratory of Oulu, PO Box 517, FIN-90101 Oulu, Finland \\ ${ }^{4}$ University of Jyväskylä, Department of Biological and Environmental Science, PO Box 35, FIN-40351 Jyväskylä, Finland
}

\begin{abstract}
During the summer months of 1991 and 1992 an increased mortality of sea trout Salmo trutta m. trutta (L.) and brown trout Salmo trutta m. lacustris (L.) occurred at a freshwater fish farm in northwestern Finland. Mortality began when the water temperature rose above $12^{\circ} \mathrm{C}$. From 1 to 6 Diphyllobothrium dendriticum (Nitzsch, 1824) larvae per fish were found in the atrium and in some cases in the ventricle of the heart in 63 to $86 \%$ of the dead $1+, 2+$ and $3+$ sea trout and brown trout in July 1991 and from June to September 1992. The fish that died showing the typical symptoms usually had this cestode larva blocking the atrioventricular orifice. In histological sections, a massive, chronic myocarditis was evident around the larva in the atrial wall. Another typical symptom of the dead fish was a ruptured atrium of the heart. Mortality caused by $D$. dendriticum was of great importance to the total mortality at the farm. Low prevalences of $D$. dendriticum larvae were also found in the hearts of fish caught live. A few encapsulated $D$. dendriticum and $D$. ditremum (Creplin, 1825) larvae were found within the visceral cavity of $10 \%$ of these fish. The probable first intermediate hosts for $D$. dendriticum in the inlet water are Eudiaptomus graciloides (Lilleborg) and Cyclops scutifer Sars. MetacerCaria of Ichthyocotylurus sp. (Trematoda) were frequently present in small numbers on the ventricle wall of sea trout and brown trout and epicarditis of different grades was observed.
\end{abstract}

KEY WORDS: Diphyllobothrium dendriticum - Diphyllobothrium ditremum Ichthyocotylurus sp. Sea trout - Brown trout - Heart - Hatchery - Mortality

\section{INTRODUCTION}

Pathological effects caused by Diphyllobothrium sp. and Diphyllobothrium dendriticum (Nitzsch, 1824) have been reported in many publications in Europe and North America. There have been some reports from the British Isles of wild salmonid losses due to these tapeworms, but the larvae were not found in the heart (Duiguid \& Sheppard 1944, Hickey \& Harris 1947, Fraser 1960). In Canada, however, they were found inside the heart in a study by Hoffman \& Dunbar (1961) in which Diphyllobothrium sp. larvae were associated with high mortalities in reared brook trout

\footnotetext{
•E-mail: riitta.rahkonen@rktl.fi
}

Salvelinus fontinalis (Mitchill). According to the description of the worms given, the species seemed to be identical or closely related to $D$. dendriticum (see Bylund 1972). Diphyllobothrium problems have also occurred in salmon hatcheries in Scotland (Sharp 1991) and in salmonid parr holding pens in a freshwater lake in Norway (Berland 1987), but no heart infection was mentioned in these papers.

In principle, the life cycle of Diphyllobothrium dendriticum involves (1) copepods as the first intermediate host (procercoid stage); (2) salmonids, coregonids, burbot Lota lota (L.) and 3-spined stickleback Gasterosteus aculeatus L. as second intermediate host (plerocercoid stage); and (3) piscivorous birds and various mammals as final host. Fish may also be infected by eating infected fish. When a larva is ingested by a host fish, it penetrates 
through the oesophagus or stomach and is usually encapsulated on the anterior part of the digestive tract and adjacent tissues or on/in other visceral organs (liver, gonads, swimbladder, peritoneum) or even in the musculature (see e.g Vik 1957, Halvorsen 1966. Henricson 1978, Andersen et al. 1987, Andersen \& Valtonen 1992).

In Finland, encapsulated Diphyllobothrium dendriticum is a common parasite in the abdominal cavity of wild salmonids and coregonids (Bylund 1966, 1972, Valtonen et al. 1988, Andersen \& Valtonen 1992), but no mortality has been reported previously from hatcheries. In autumn 1968, an epizootic leading to the death of vendace Coregonus albula L. was reported from one eastern Finnish lake (Bylund 1972), and all dead fish examined had a $D$. dendriticum plerocercoid inside the heart. Bylund (1966, 1972) also found heavily infected wild salmonids in Lake Inari, northern Finland, with numerous adhesions and centres of granulation tissue in mesenteries and between viscera, but larvae were not found in the heart.

A mortality associated with the presence of cestode larvae of Diphyllobothrium dendriticum was observed at Muonio Fish Farm, northwestern Finland, in July 1991. According to the late fish farmer E. Puhakka, varying undiagnosed mortality had occurred there over the years at about the same time each summer.

The purpose of this study was to collect information about the proportion of Diphyllobothrium dendriticum induced mortality at the farm, timing of mortality, and the degree of heart infection among fish before stocking as well as information about the pathogeny of $D$. dendriticum larvae, which are important when stocking results are analysed.

\section{MATERIALS AND METHODS}

The Muonio Fish Farm (owned by the Finnish Game and Fisheries Research Institute) is situated in the River Tornion-Muonionjoki basin, on the Lake Särkjjärvi watercourse (Fig. 1). In 1991-1993, the farm produced sea trout Salmo trutta m. trutta (L.), brown trout Salmo trutta m. lacustris (L.). Arctic char Salvelinus alpinus (L.) and land-locked salmon Salmo salar m. sebago Girard fingerlings, smolts and brood fish in earth ponds outside and in rearing tanks inside the farm building. Fish are fed with commercially available dry pellets. The farm takes its water primarily from Lake Särkijärvi, which is $4.8 \mathrm{~km}^{2}$ in size, shallow (mostly 2 to $5 \mathrm{~m}$ ) and eutrophic (Olin 1936, Salo 1995). The $400 \mathrm{~mm}$ water intake tube is situated at a depth of $3 \mathrm{~m}$. Fish species in the lake include whitefish Coregonus spp., vendace Coregonus albula L., perch Perca fluviatilis (L.), burbot Lota lota (L.), pike Esox lucius L., some ruffe Gymnocephalus cernuus (L.) and brown

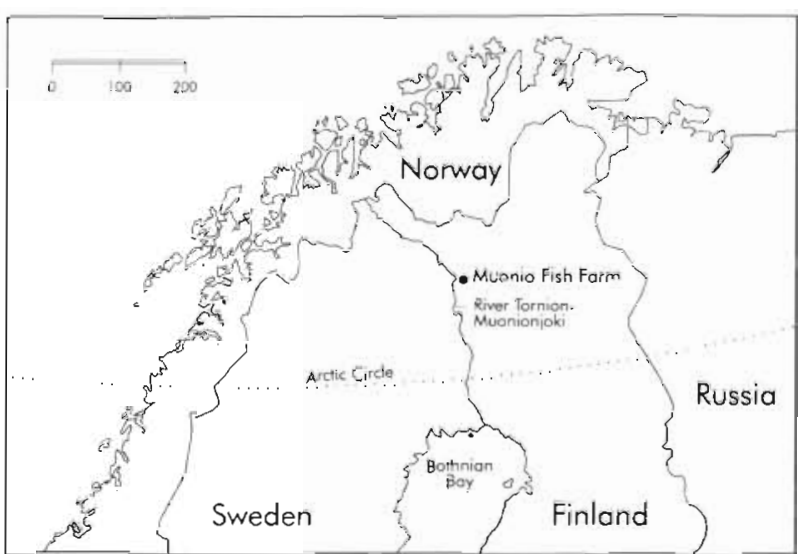

Fig. 1. Site of the Muonio Fish Farm, northwestern Finland

trout. Ice cover is present from October until late May/early June. A few gull Larus spp. and tern Sterna spp. species are common in summer.

Parasitological samples. In July 1991, the heart was examined for Diphyllobothrium spp. in 786 fish found dead in the tanks and ponds: sea trout aged $1+(\mathrm{n}=52)$ and $2+(n=432)$, brown trout aged $2+(n=279)$, landlocked salmon aged $1+(n=1.8)$, Arctic char aged $1+$ $(n=5)$. The heart was also examined from 51 normally behaving fish sampled alive: $1+$ sea trout $(n=10), 2+$ sea trout $(n=31)$ and $2+$ brown trout $(n=10)$.

In 1992, most of the dead fish were collected from early June until the end of September Heart samples were taken from 763 fish. The fish examined included 185 brown trout in their first summer and 48 individuals in their second summer while for sea trout the numbers were 132 and 172, respectively; 192 fish were examined in their third summer and 34 in their fourth. In addition, inner organs were examined from $1+(\mathrm{n}=$ $88)$ and $2+(n=100)$ sea trout. As in 1991, live fish were also caught and examined: $1+$ sea trout $(n=30)$ and brown trout $(\mathrm{n}=31)$.

In 1993, dead 1 yr old trout were collected from March until the middle of June and examined immediately, in total 80 sea trout and 48 brown trout. The heart and internal organs were examined for Diphyllobothrium spp. In March 1993, samples were taken from sea trout destined for spring stocking, in total 90 ( 1 yr old) and 49 ( 2 yr old) trout

Cysts of Ichthyocotylurus sp. (Trematoda) metacercaria were counted on the ventricle walls of both trout species aged $0+(n=215)$ in 1992, as well as in samples from 1 and 2 yr old fish taken in spring $1993(n=138)$.

The chi-squared test $\left(\chi^{2}\right)$ was used to test the prevalence of heart infection in fish caught dead and alive.

Plankton samples. Plankton samples were taken from inlet water entering one tank from the beginning of May until the end of August 1993. The mesh size 
of the plankton net was $50 \mu \mathrm{m}$, and the water volume 1001 in May and 2001 thereafter. The sample was preserved in $70 \%$ ethanol. The species and developmental stage identification of cyclopoid and calanoid copepods was done by inspecting either whole samples or small parts of them on a watch glass with a microscope and then making glycerine preparations from whole or dissected plankton for closer examination.

Methods for examining fish and worms. The total length and weight of the fish were measured and the heart atrium and ventricle were opened separately under the microscope using 10× magnification. In 1992 and 1993 the viscera was examined macroscopically with the aid of forceps to find the free and encapsulated larvae. The musculature of the fish was not studied. Worms from fresh fish were fixed immediately in $70 \%$ ethanol.

A total of 150 fixed specimens from the hearts of $2 \mathrm{yr}$ old trout were measured under a microscope in July 1991. Worms from 1 to $3 \mathrm{yr}$ old deep frozen sea trout were measured in 1992. In 1993, fixed worms were measured from 1 yr old trout in the spring species identification from alcohol-fixed heart larvae was confirmed by Dr K. Andersen, University of Oslo.

Histology, bacteriology and virology. During the peak of mortality in 1991 and 1992, the normal autopsy and examination of the presence of ectoparasites on gills and skin and bacteriological examination were carried out according to Midtlyng et al. (1992). A sample of gill, skin, heart, liver, anterior and posterior kidney, spleen and pyloric caeca from moribund fish was fixed in neutral buffered 10\% formalin, embedded in paraffin and stained with haematoxylin and eosin. For the bacteriological examination, swabs from kidney and intestinal contents were streaked onto bovine blood agar (tryptic soy agar, CASO, Merck, containing 5\% blood) and modified Shotts Waltman agar. The medium contained $0.03 \%$ bromthymol blue instead of the $0.0003 \%$ suggested in the original article by Waltman \& Shotts (1984). The agar plates were incubated aerobically at $22^{\circ} \mathrm{C}$ for $7 \mathrm{~d}$. For the virological examination, the methodology presented in Midtlyng et al. (1992) was applied to the incubation of cultures inoculated in BF-2, (bluegill fry) RTG-2 (rainbow trout gonad), FHM (fathead minnow) or CHSE (chinook salmon embryo) cells
(2 to 3 cell lines per virological examination) at $15^{\circ} \mathrm{C}$.

\section{RESULTS}

\section{Mortality of sea trout and brown trout}

In 1991, a clear peak occurred in the mortality of both species in July (Fig. 2). Clinically healthy fish unexpectedly began to show violent swimming movements and died within a few minutes. Sudden deaths were observed in particular when fish were disturbed. In 1992. a mortality peak was not observed, but increased mortality took place in the sea trout of both age groups during June to September (Fig. 3). The mean afternoon temperature was about $2^{\circ} \mathrm{C}$ higher in July $1991\left(15.3^{\circ} \mathrm{C}\right)$ than in July $1992\left(13.6^{\circ} \mathrm{C}\right)$ (Figs. 2 \& 3). Because of extensive rebuilding activities at the farm, exact mortality data for summer 1993 are not available.

\section{Prevalence and intensity of the parasite infection}

In July 1991, the prevalence of the intracardial Diphyllobothrium dendriticum infection in dead sea
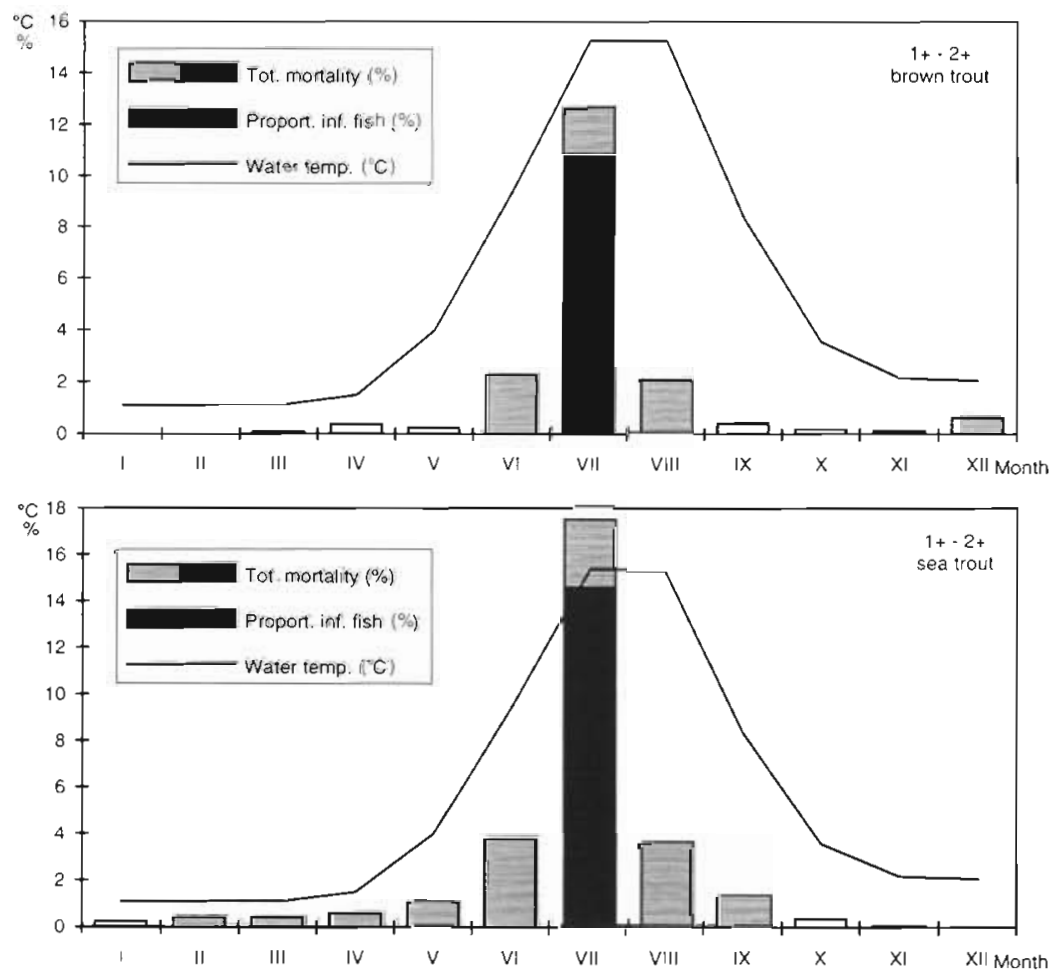

Fig. 2. Salmo trutta m. Lacustris and m. trutta. Monthly mortality (\%) of brown trout and sea trout aged $1+$ to $2+$ and proportion (= prevalence of infection in relation to the height of the column) of Diphyllobothrium dendriticum infected fish (\%) at the Muonio Fish Farm in July 1991 

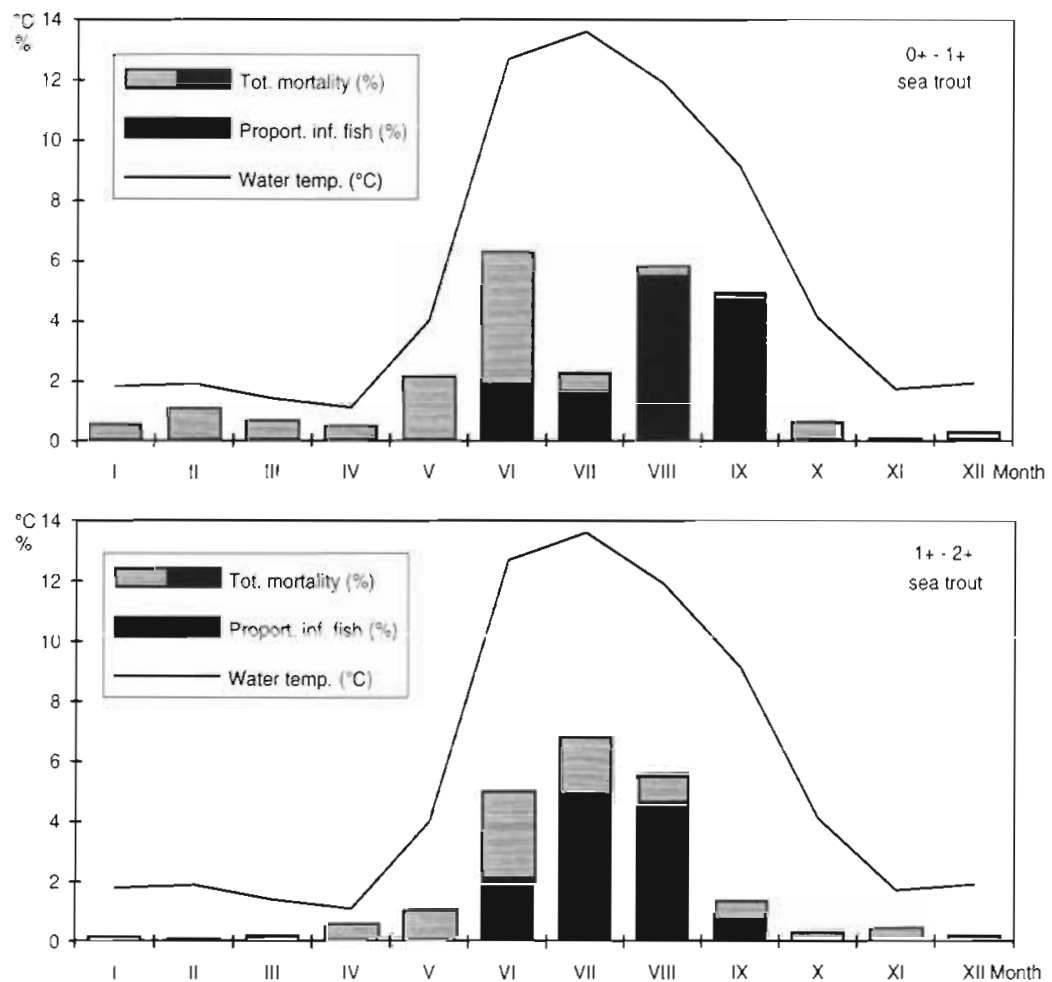

Fig. 3. Salmo trutta m. trutta. Monthly mortality $(\%)$ of sea trout aged $0+$ to $1+$ and $1+$ to $2+$ and the proportion (= prevalence of infection in relation to the height of the column) of Diphyllobothrium dendriticum infected fish (\%) at Muonio Fish Farm in June to September 1992 trout and brown trout varied from 73 to $86 \%$ (Table 1$)$. In addition, 15 out of the 18 land-locked salmon which were opened and 3 of the 5 Arctic char examined also harboured one $D$. dendriticum larva per fish within the heart in 1991. The prevalence of $2+$ trout infection is illustrated in Fig. 2, where it is related to the height of the column. The average number of larvae per infected heart varied between 1.1 and 1.5 , with a maximum of 6 worms in an atrium (Table 1). The average length of the alcohol-fixed worms in the hearts of $2+$ sea trout and brown trout was $5.1 \mathrm{~mm}$ (SD $1.1 \mathrm{~mm}$, min 2.5 $\max 9.5 \mathrm{~mm}, \mathrm{n}=150$ ) in July 1991. In samples taken from fish caught live the prevalence of heart infection varied from 10 to $39 \%$ with 1 to 2 worms per infected heart (Table 2). The prevalence difference between fish of the same age caught live and dead was always significant using the $\chi^{2}$ test ( $p<0.001$ in all cases).

In 1992, the prevalences of infection were about the same level as in 1991 (Table 1 ; for sea trout see also Fig. 3 ).

Table 1. Occurrence of Diphyllobothrium dendriticum in the hearts of dead sea trout and brown trout at the Muonio Fish Farm, northwestern Finland, between 1991 and 1993

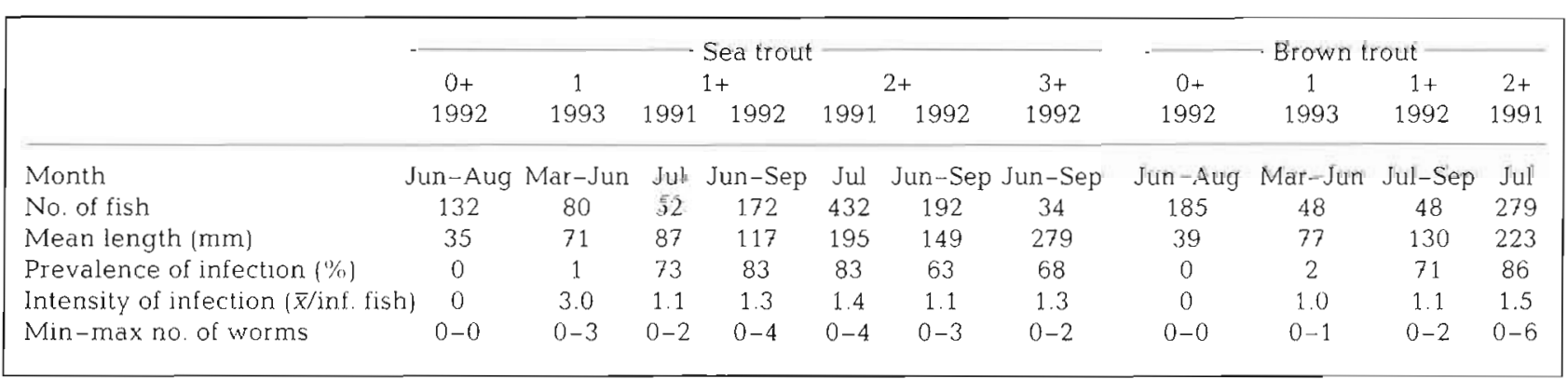

Table 2. Occurrence of Diphyllobothrium dendriticum in the hearts of sea trout and brown trout caught live at the Muonio Fish Farm, northwestern Finland, between 1991 and 1993

\begin{tabular}{|c|c|c|c|c|c|c|c|c|c|}
\hline & \multicolumn{5}{|c|}{ Sea trout } & \multicolumn{4}{|c|}{ - Brown trout } \\
\hline & \multirow{2}{*}{$\begin{array}{c}1 \\
1993\end{array}$} & \multicolumn{2}{|r|}{$1+$} & \multirow{2}{*}{$\begin{array}{c}2 \\
1993\end{array}$} & \multirow{2}{*}{$\begin{array}{c}2+ \\
1991\end{array}$} & \multirow{2}{*}{$\begin{array}{c}1 \\
1993\end{array}$} & \multirow{2}{*}{$\begin{array}{c}1+ \\
1992\end{array}$} & \multirow{2}{*}{$\begin{array}{c}2 \\
1993\end{array}$} & \multirow{2}{*}{$\begin{array}{c}2+ \\
1991\end{array}$} \\
\hline & & 1991 & 1992 & & & & & & \\
\hline Month & Mar & Jul & Jul, Sep & Mar & Jul & Mar & Jul, Sep & Mar & Jul \\
\hline No. of fish & 59 & 10 & 30 & 26 & 31 & 31 & 31. & 23 & 10 \\
\hline Mean length $(\mathrm{mm})$ & 75 & 86 & 120 & 158 & 192 & 80 & 128 & 174 & 223 \\
\hline Prevalence of infection (\%) & 0 & 10 & 13 & 19 & 39 & 0 & 0 & 4 & 30 \\
\hline Intensity of infection ( $\bar{x} /$ inf. fish) & 0 & 1.0 & 1.0 & 1.0 & 1.2 & 0 & 0 & 1.0 & 1.0 \\
\hline Min--max no. of worms & $0-0$ & $0-1$ & $0-1$ & $0-1$ & $0-2$ & $0-0$ & $0-0$ & $0-1$ & $0-1$ \\
\hline
\end{tabular}


The mean intensity of intracardial infection varied from 1.1 to 1.3 larvae per infected fish (Table 1). The average length of deep-frozen worms in 1992 increased with the age of the fish: $2+$ sea trout, $13.0 \mathrm{~mm}$ (SD 4.4), $\mathrm{n}=25 ; 3+$ sea trout, $15.2 \mathrm{~mm}$ (SD 5.4), $\mathrm{n}=45$; $4+$ sea trout, $30.7 \mathrm{~mm}$ (SD 8.2), $\mathrm{n}=6$.

Worms were not found in the hearts of dead fish during their first summer and autumn in 1992 (Table 1). One larva was found free in the ventral cavity of one $0+$ brown trout in July, but the species could not be identified. One to two encapsulated larvae were found on the stomach and pyloric region as well as on the liver in $10 \%$ of the $1+$ and $2+$ sea trout. Because the fish were mostly deep-frozen, Diphyllobothrium ditremum and D. dendriticum were not distinguishable. However, encapsulated $D$. ditremum was confirmed on the stomach in some of the fresh fish. In the fish caught live the prevalence of heart infection varied from 0 to $13 \%$ with 1 worm per infected heart in 1992 (Table 2). As in 1991, the difference in the prevalence of infection between fish of the same age caught dead and caught live was always significant using the $\chi^{2}$ test $(p<0.001$ in all cases).

In 1993, small Diphyllobothrium dendriticum appeared on the alimentary tract, liver and on the heart of $7.5 \%$ of the dead 1 yr old sea trout and on $4.2 \%$ of the brown trout from the middle of May until the middle of June. Only 1 worm was found to be encapsulated. In addition (Table 1), 1 sea trout harboured 3 small worms while 1 brown trout had 1 worm inside the heart. The average length of the fixed worms was $1.5 \mathrm{~mm}$ (SD $0.8 \mathrm{~mm}$, $\min 0.5, \max 3.5 \mathrm{~mm}$, $\mathrm{n}=11)$.
Among fish caught live that were examined before stocking in March 1993, 1 yr old fingerlings were not infected, while $19 \%$ of the 2 yr old sea trout and $4 \%$ of the brown trout harboured 1 larva per fish in the heart (Table 2). The length of the fixed worms $(10$ to $15 \mathrm{~mm}$ ) indicated that the fish had been infected during the previous summer or autumn.

Ichthyocotylurus sp. cysts were present from August onwards in 0+ trout in 1992. In. samples from spring 1993, the prevalence of infection in 1 yr old trout was 30 to $50 \%$ with 1 to 2 cysts per heart, and among 2 yr old trout 50 to $100 \%$, with 4 to 5 cysts on average.

\section{Pathology}

Usually, the location of Diphyllobothrium dendriticum was in the atrium of the heart (Fig. 4). In many cases, the parasite blocked the atrioventricular orifice (Fig. 5). Occasionally, a rupture in the atrium and bleeding into the pericardial cavity was found. Histologically, there was usually a massive chronic myocarditis around the larva in the atrial wall. Intramural haemorrhages of different ages were also seen even in fish without a heart rupture. The other specific lesion evident in the heart sections was epicarditis, the grade of which varied from mild, superficial inflammatory cell infiltration to profound epicarditis extending to the stratum compactum of the ventricle wall. Structures resembling metacercaria of Ichthyocotylurus sp. were associated with this lesion. No bacterial or viral infection was observed in normal health control samples from 1991 to 1993.

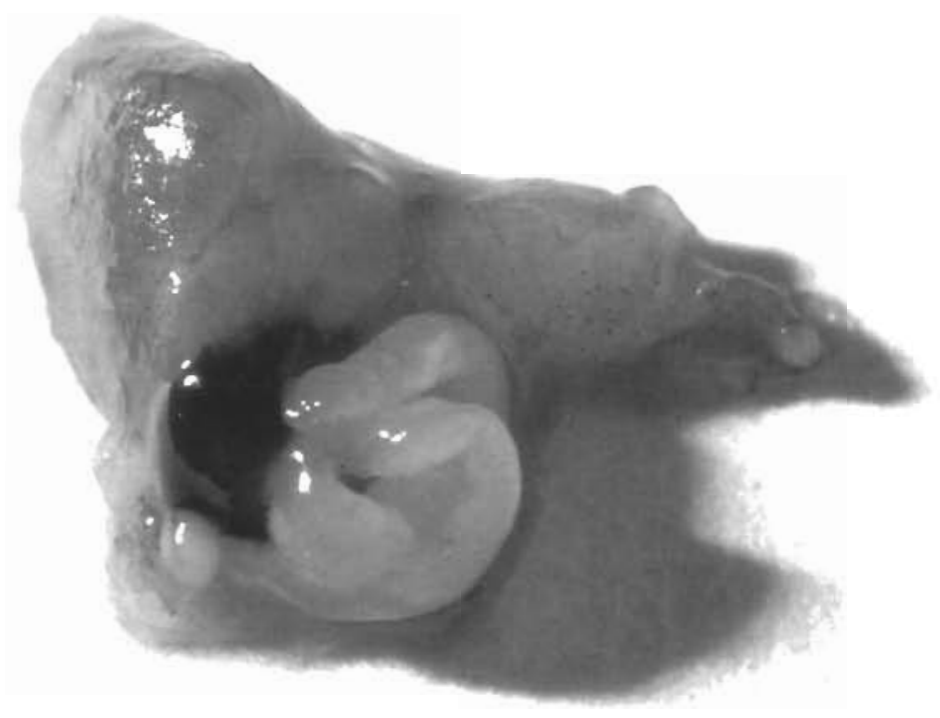

Fig. 4. Diphyllobothrium dendriticum. Larva removed from the atrium of a 2 yr old sea trout

\section{Copepoda species in the inlet water}

The copepodid stages of Cyclops spp. were found throughout the whole period sampled, i.e. from the beginning of May to the end of August. Adults of C. scutifer Sars were found in the early part of summer in just one sample but in August in greater numbers. A low number of adult Acanthocyclops robustus (Sars) was found in May and July-August, and greater numbers of copepodid stages in July. The greatest number of the subfamily Eucyclopinae, mainly Paracyclops fimbriatus (Fisher), was found in July. The calanoid Eudiaptomus graciloides (Lilleborg), which occurred mainly as copepodids, had one peak in May and another mass occurrence from the end of June onwards, achieving a maximum of 10000 ind. per $100 \mathrm{l}$ at the end of August. 


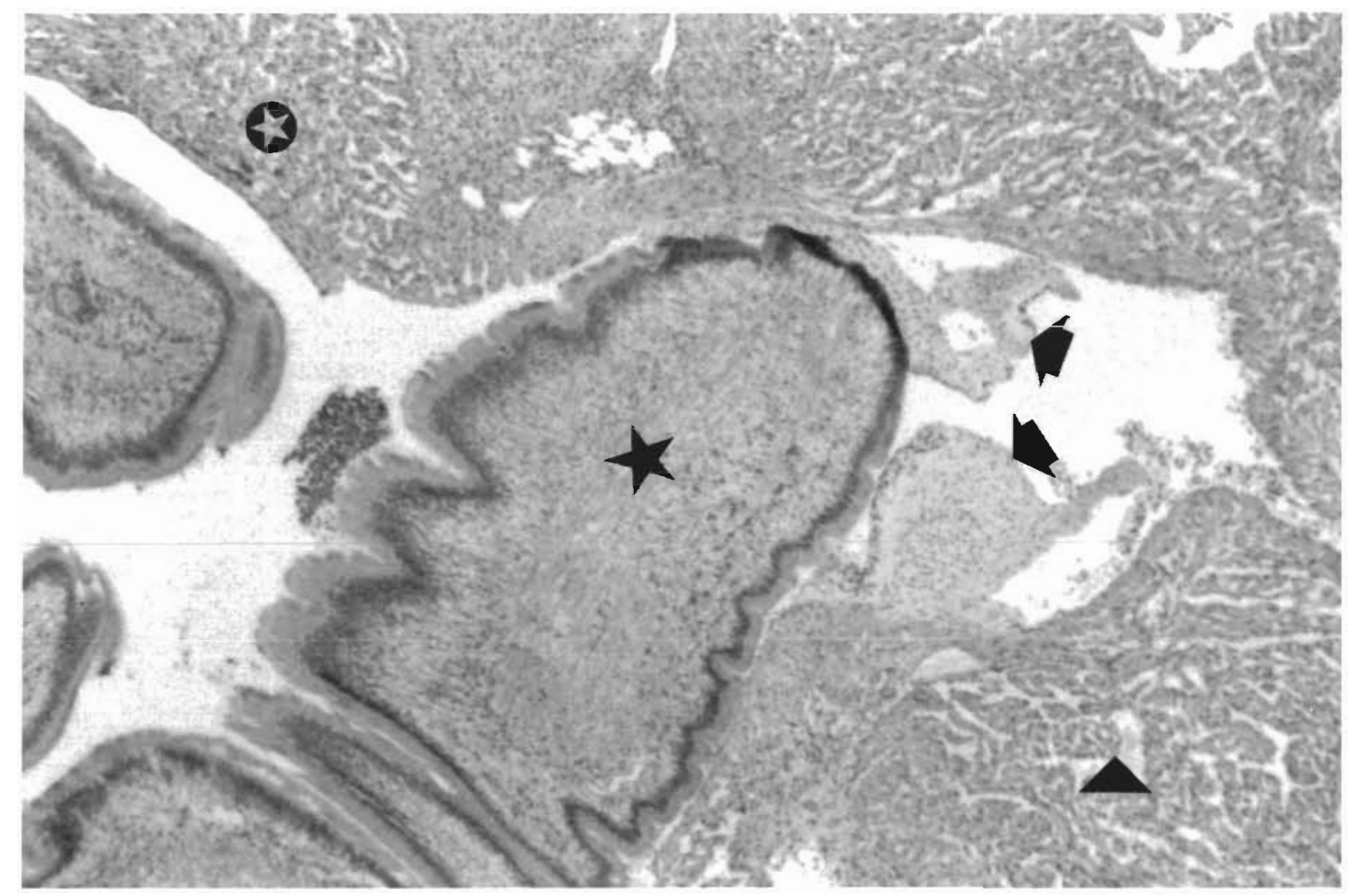

Fig. 5. Diphyllobothrium dendriticum blocking the atrioventricular orifice in the atrium of the heart of sea trout. ( Ventral valves; (A) wall of the ventricle; $(\$)$ atrium; $(\star)$. dendriticum in the atrium of the heart. H\&E, 10x

\section{DISCUSSION}

The high prevalence of intracardial infection of dead fish older than 1 yr with Diphyllobothrium dendriticum shows that mortality and infection are strongly associated with each other. The symptoms seen in dying fish and the pathoanatomical lesions in the infected heart suggest that $D$. dendriticum was the direct cause of death in a large proportion of the dead fish. On the basis of these facts and in the absence of other pathogens it is concluded that $D$. dendriticum causes considerable mortality in sea trout and brown trout in their second and especially in their third summers at the Muonio Fish Farm.

The observed base mortality also seemed to be related to water temperature. Causes for this increase may be stress related and/or the indirect effects of Diphyllobothrium sp., Ichthyocotylurus sp. and other parasites.

It seems clear that fish are not infected earlier than at the beginning of their second summer, i.e. when they are about 1 yr old. The reason for this might be that the Diphyllobothrium dendriticum larvae do not develop in such small fish.
Fraser (1960) and Hickey \& Harris (1947) have observed a peak in the mortality caused by Diphyllobothrium sp. infection on internal organs taking place at the warmest time of summer, in July and August. The increase in mortality took place at the Muonio Fish Farm when the water temperature was $12^{\circ} \mathrm{C}$ or higher. The high mortality peak and pathogeny caused by $D$. dendriticum in 1991 might be connected to the sharp rise in the water temperature that summer. In 1992 , increased mortality can be explained by the $D$. dendriticum infection, apart from June. The exceptionally high mortality in June might be a consequence of the fish taggings in May. Hickey \& Harris (1947) showed experimentally that the plerocercoids were inactive at $10^{\circ} \mathrm{C}$, moved slowly at $12^{\circ} \mathrm{C}$, were active at $14^{\circ} \mathrm{C}$ and left their capsules on internal organs within a few minutes at a temperature of $15^{\circ} \mathrm{C}$.

It is clear that when the activity of a worm (worms) inside the heart increases at summer temperatures, it has fatal consequences. In addition, it is known that with fish, stroke volume and heart rate increase with increasing water temperature (Laitinen 1995) and thus damage to the heart and increased resistance to blood flow caused by Diphyllobothrium dendriticum become more serious at higher temperatures. 
It is unlikely that all fish with a heart infection will die. A low prevalence was observed among live fish caught in summer. However, it is possible that these fish will die later in the summer due to the parasite. On the other hand, infected trout were found at low water temperatures in March 1993, when $19 \%$ of 2 yr old sea trout and $4 \%$ of brown trout of the same age were found to be infected without increased mortality. It seems possible that trout were able to withstand heart worms at least at winter temperatures.

Abdominal infection by Diphyllobothrium sp. and $D$. dendriticum plerocercoids have been reported to cause, e.g., different stages of haemorrhages, tissue necrosis, peritonitis, inflammations, severe anaemia and different stages of adhesions depending on the number of larvae, all of which may cause mortality (Hickey \& Harris 1947, Fraser 1960, Hoffman \& Dunbar 1961, Bylund 1966, 1972, van Kruiningen et al. 1987). In this study, only a few capsules of $D$. dendriticum occurred on the visceral organs so typical abdominal symptoms did not occur. So far, the only reported heart infections with $D$. dendriticum were in reared brook trout in Canada (Hoffman \& Dunbar 1961) and in wild vendace in Finland (Bylund 1972).

According to Halvorsen \& Andersen (1984), Weiland \& Meyers (1989) and Rodger (1991), Diphyllobothrium ditremum has also caused severe pathological damage and sometimes high mortality. At the Muonio Fish Farm, both the prevalence and intensity of $D$. ditremum capsules were very low and visible damage or adhesions were not observed.

Pathogeny of metacercariae of Ichthyocotylurus sp. is not well documented in the literature. However, 10 to $100 \mathrm{I}$. erraticus cysts on the heart caused severe epicarditis and some mortality among 3 yr old rainbow trout at the Tervo fish breeding station in eastern Finland in the autumn and winter of 1994-95 (I. Rissanen \& T. Pohjanvirta pers. comm.). On the other hand, some epicarditis and myocarditis have been common even in wild fish without any causative agent (Haaparanta et al. 1993). It might be assumed that the epicarditis induced by a few Ichthyocotylurus sp. cysts at the Muonio Fish Farm worsened the condition of trout in general, and thus together with the heart worm might be of some importance to mortality.

According to Henricson (1978), Diphyllobothrium dendriticum infection took place mainly in SeptemberOctober and the most important Copepoda species which served as the first intermediate host was $C y$ clops strenuus, which overwinter as adults. Halvorsen (1966) has reported that $C$. strenuus adults and juveniles are susceptible to $D$. dendriticum larvae, and that there is no seasonal variation with respect to susceptibility. The growth of the procercoid inside plankton is temperature dependent. Cercomers are fully devel- oped within $14 \mathrm{~d}$ at $20^{\circ} \mathrm{C}$, and within 42 to $52 \mathrm{~d}$ at $6^{\circ} \mathrm{C}$ (Halvorsen 1966). At the Muonio Fish Farm the 0+ trout were not infected. According to the results from spring 1993, 1 yr old trout received their first worms in the middle of May. Since water temperatures are low in winter and spring at the Muonio Fish Farm, it is clear that fish obtained worms via overwintered infected juvenile or adult copepods.

Of the copepod species found in inlet water at Muonio, Cyclops scutifer has been confirmed experimentally to serve as the first intermediate host for Diphyllobothrium dendriticum (see Halvorsen 1966. Henricson 1978). Eudiaptomus graciloides might be another possibility, since it is a close relative to E. gracilis (Sars), which has been experimentally confirmed as being a first intermediate host (Halvorsen 1966). E. graciloides was clearly the most abundant species of Copepoda during the summer.

According to the literature, the heart infection caused by Diphyllobothrium dendriticum could be considered an uncommon phenomenon at fish farms as well as in wild fish, although this parasite species is often present in capsules in the abdominal cavity in salmonids. The reasons for the rare occurrence of the worms remain unclear. Further experimental work is needed to determine whether there is a question of a 'local worm stock' which penetrates the heart more commonly.

Another possibility is that the observed phenomenon occurs regularly in wild fish but has been overlooked because weakened and moribund fish are soon preyed upon by predators. Mass mortalities, as seen in vendace in eastern Finland (Bylund 1972), are more likely to arouse attention and though such mass mortalities might indicate that Diphyllobothrium dendriticum has an influence on salmonid populations, this is difficult to demonstrate.

However, wild sea trout and brown trout spend their first years in a river habitat where suitable lacustrine first intermediate hosts for Diphyllobothrium dendriticum are unlikely to occur. It is thus clear that this parasite is able to infect farmed fish at hatcheries only when inlet water is taken from a lake where a strong $D$. dendriticum population occurs in wild fish. Salmonid parr may also become very heavily and fatally infected with Diphyllobothrium plerocercoids when they are kept in holding pens in freshwater lakes where wild salmonids also occur (Berland 1987). Infected copepods enter the Muonio Fish Farm via inlet water from the shallow Lake Särkijärvi. Although the fish feed mainly on dry pellets, they also consume copepods from the inlet water which can be seen in the present results. The most probable second intermediate hosts in Lake Särkijärvi are whitefish, burbot and trout (see e.g. Andersen \& Valtonen 1992), but their parasites were not studied. 
However, $D$. dendriticum has been confirmed as occurring in whitefish from nearby Lake Äkäsjärvi (Rahkonen unpubl. data).

This study revealed that intracardial infection by Diphyllobothrium dendriticum caused considerable mortality at the Muonio Fish Farm and that as many as $20 \%$ of $2 \mathrm{yr}$ old, stockable-sized sea trout might carry D. dendriticum larvae inside the heart. Sea trout fingerlings are stocked from the farm into the River Tornion-Muonionjoki, where the natural sea trout stock is weak. The value of infected smolts is questionable in stocking, and this is one reason why the practice at the farm has been changed so that the trout have been stocked as 1 yr old parrs since 1994. Other possible ways to prevent infection at the farm are to filter the inlet water or lead ine inlake tube so that it is deeper.

Knowledge of the dynamics of the Diphyllobothrium dendriticum infection is needed to prevent mortality cases such as those which occurred at the present fish farm. However, this study raises the question of whether the observed phenomenon also occurs in wild salmonids in lakes. Regulation of the host population by parasites is poorly understood (Esch \& Fernández 1993), and more detailed studies are needed in that area.

Acknowledgements. We are indebted to the staff of the Muonio Fish Farm for their kind help in collecting the dead fish from the ponds and tanks. We are grateful to Dr K. Andersen for her kind assistance in the identification of Diphyllobothrium dendriticum, and to Assoc. Prof. E. Tellervo Valtonen for her critical comments on the manuscript. Veterinarians Katarina Kulonen and Varpu Hirvelä-Koski, National Veterinary and Food Research Institute, Helsinki and Oulu, kindly performed the virological and bacteriological tests.

\section{LITERATURE CITED}

Andersen K, Ching HL, Vik R (1987) A review of freshwater species of Diphyllobothrium with redescriptions and distribution of $D$. dendriticum (Nitzsch, 1824) and $D$. ditremum (Creplin, 1825) from North America. Can J Zool 65:2216-2228

Andersen KI, Valtonen ET (1992) Segregation and cooccurrence of larval cestodes in freshwater fishes in the Bothnian Bay, Finland. Parasitology 104:161-1.68

Berland B (1987) Helminth problems in sea-water aquaculture. In: Stenmark A, Malmberg M (eds) Parasites and diseases in natural waters and aquaculture in Nordic countries. Zoo-Tax, Naturhistoriska Riksmuseet, Stockholm, p 56-62

Bylund $G$ (1966) Förekomsten av difyllobotrida plerocercoider i fisk från Enare sjö. Institute of Parasitology, Abo Akademu, Abo, Finland. Information 6:48-56

Bylund G (1972) Pathogenic effects of a diphyllobothriud plerocercoid on its host fishes. Societas Scientarum Fennica, Helsing fors Commentationes Biologicae 58:1-11
Duiguid JB, Sheppard EM (1944) A Diphyllobothrium epidemic in trout. J Pathol 56:73-80

Esch GW. Fernández JC (1993) A functional biology of parasitism. Ecological and evolutionary implications. Chapman \& Hall, University Press, Cambridge

Fraser PG (1960) The occurrence of Diphyllobothrium in trout, with special. reference to an outbreak in the West of England. J Helminthol 34:59-72

Haaparanta A, Valtonen ET, Hoffmann RW (1993) Heart inflammation in perch Perca fluviatilis and roach Rutilus rutilus from central Finland. Dis Aquat Org 17:25-32

Halvorsen O (1966) Studies of the helminth fauna of Norway VIII: an experimental investigation of copepods as first intermediate hosts for Diphyllobothrium norvecicum Vik (Cestoda). Nytt Mag Zool 13:83-117

Halvorsen O, Andersen K (1984) The ecological interaction between Arctic char, Salvelinus alpinus (L.), and the plerocercoid stage of Diphyllobothrium ditremum. J Fish Biol 25:305-316

Henricson J (1978) The dynamics of infection of Diphyllobothrium dendriticum (Nitzsch) and $D$ ditremum (Creplin) in the char Salvelinus alpinus (L.) in Sweden. J Fish Biol 13: $51-71$

Hickey MD, Harris JR (1947) Progress of the Diphyllobothrium epizootic Poulaphouca Reservoir, Co. Wicklow, Ireland. J Helminthol 22:13-28

Hoffman GL, Dunbar CE (1961) Mortality of eastern brook trout caused by plerocercoids (Cestoda: Pseudophyllidea: Diphyllobothriidae) in the heart and viscera. J Parasitol 47 399-400

van Kruiningen HJ, Placke ME, Wojan LD (1987) Diphy]lobothrium plerocercoid infestation in landlocked salmon Vet Pathol 24:285-286

Laitinen M (1995) Biomonitoring of the responses of fish to environmental stress. Dr thesis, Biological Research Reports from the University of Jyväskylä 43

Midtlyng PJ, Helgason S, Jansson E, Mortensen A, RimailaParnänen E (1992) Nordic manual for the surveillance and diagnosis of diseases in farmed salmonids. Nordiske Seminar- og Arbejdsrapporter 1992:545, Copenhagen, Denmark

Olin TV (1936) Die Wassergebiete Finnlands und ihre Seen Meddelanden från Hydrografiska Byrån VII, Statsrådets tryckeri, Helsinki

Rodger HD (1991) Diphyllobothrium sp. infections in freshwater-reared Atlantic salmon (Salmo salar L.). Aquaculture $95: 7-14$

Salo O (1995) Results from the water monitoring at Muonio Fish Farm in 1994. Lapın Vesitutkimus Oy, Rovaniemi (in Finnish)

Sharp GJE (1991) Worms - a further cause for concern? Fish Farmer 14:42-43

Valtonen ET, Brummer-Korvenkontıo H, Rahkonen R (1988) A survey of parasites of coregonids from three water bodles in Finland. Finn Fish Res 9:313-322

Vik R (1.957) Studies of the helminth fauna of Norway. I. Taxonomy and ecology of Diphyllobothrium norvecicum n. sp. and plerocercoid of Diphyllobothrium latum (L.). Nytt Mag Zool 5:25-93

Waltman DW, Shotts EB (1984) A medium for the isolation and differentiation of Yersinia ruckeri. Can J Fish Aquat Sci 41:804-806

Welland KA, Meyers TR (1989) Histopathology of Diphyllobothrium ditremum plerocercolds in coho salmon Oncorhynchus kisutch. Dis Aquat Org 6:175-1.78 